centration of metals in the atmosphere could be many hundred negative powers of ten.

If the hydrogen layer is sufficiently thick, the metal lines should, thus, not appear in the spectrum. This case should correspond to stars like Wolf 489 or $\mathrm{O}_{2}$ Eridani $B$. The presence of metal lines in the spectra of some white dwarfs is only possible when the hydrogen layer is very thin and the concentration of heavy elements great at the bottom of the nondegenerate outer part of the star. Convection currents, such as those found by Unsöld, could then carry heavy elements to the very surface of the star. This seems to be the model for a star like Van Maanen 2. The great proximity of heavy elements to the surface, and such convection currents, would be sufficient to explain the presence in the spectrum of lines of light metallic elements like calcium. The theory of production of lines in stellar atmospheres also indicates that collision damping should be sufficient to explain the broadening of lines of $\mathrm{Ca}^{+}$. The weakness of lines of heavy elements such as iron should be connected with the strong separation of heavier elements in the gravitational field.

Such considerations about the thickness of the hydrogen layer agree also with calculations on the energy production. The main source of energy is represented by the reaction

$$
{ }^{1} \mathrm{H}+{ }^{1} \mathrm{H} \rightarrow{ }^{2} \mathrm{D}+e^{+},
$$

and the ensuing reactions, the rate of which has been calculated by Bethe and Critchfield ${ }^{3}$. This rate is much greater than that corresponding to processes in the mixed layer, analogous to those occurring in the sun. For the white dwarfs we get in this manner an estimate for the thickness of the hydrogen layer which should be responsible for the actual energy production and which, in fact, turns out to be large compared with the thickness of the mixed layer for $\mathrm{O}_{2}$ Eridani $B$ and Wolf 489, and extremely small in the case of Van Maanen 2.

A more detailed account of the above ideas based on a fuller discussion of the constitution of the various types of white dwarfs will be given in a later paper. I wish to thank Prof. B. Strömgren for stimulating discussions on the subject.

Observatory,

University of Copenhagen, and

Institut d'Astrophysique, Paris.

Nov. 12.

' Blackett, Nature, 159, 658 (1947).

Schatzman, Ann. Astrophys., 8, 143 (1945).

${ }^{3}$ Bethe and Critchfleld, Phys. Rev., 54, 248 (1938).

\section{The Bikini Bomb and the Seismology of the Pacific Region}

Gutenberg and Richter ${ }^{1}$ have recently published numerical travel-time data for $P$ waves recorded at eight stations in the United States, following the detonation of an atomic bomb over Bikini on 1946 July 24. They point out the importance of these waves in checking travel-time tables, and use the results to test the accuracy of earlier tables ${ }^{2}$ published by them. The purpose of this note is to compare the data with the Jeffreys - Bullen tables ${ }^{3}$; and, further, to investigate the precision with which the result of this comparison may be applied to the question of the structure of the Pacific region.
The eight recording stations were at distances from the place of detonation ranging from $69^{\circ}$ to $78 \cdot 6^{\circ}$. The excesses of the 'observed' travel-times of the first $P$ waves over the times given in the JeffreysBullen tables are found to be $-1 \cdot 6,-0 \cdot 4,-1 \cdot 6$, $-2 \cdot 1,-1 \cdot 1,-2 \cdot 7,-1 \cdot 1,-0 \cdot 4$ sec., yielding a mean of $-1.4 \pm 0.7 \mathrm{sec}$. (the time of detonation of the bomb is known within 0.1 sec.). To this must be added the mean ellipticity correction ${ }^{4}$ of -0.4 sec., giving a mean residual of $-1.8 \pm 0.7$ sec. ( $\mathrm{It}$ is assumed that the data of Gutenberg and Richter relate to geocentric and not geographic latitudes.)

A residual of this order is to be expected, because of special features of the Pacific structure ${ }^{5}$. Thus the results of the Bikini bomb suggest no improvements to the Jeffreys-Bullen tables for epicentral distances of the order of $70^{\circ}-80^{\circ}$.

On independent grounds, the Jeffreys - Bullen $P$ tables are indicated as being accurate within standard errors of the order of 0.4 sec. for 'average' earthquakes. This would indicate that the travel time of $P$ waves between Bikini and stations in the United States is less by $1.8 \pm 0.8$ sec. than the corresponding travel-times for average earthquakes (in which epicentres are in continental regions). This figure may be of some importance in subsequent investigations of the Pacific region.

University of Sydney. Sept. 12.

1 Trans. Amer. Geophys. Union, 27, 776 (1946).

Gerlands Beitr. 2. Geophy8., 54, 94 (1939).

- British Association, Gray Milne Trust (1940).

- Bullen, Mon. Not. Roy. Ast. Soc., Geophys. Suppl., 4, 143 (1937).

- See, for example, Bullen, "Theory of Seismology", 203, 209 (Camb. Univ. Press, 1947).

\section{Sublimation in the Atmosphere over the Oceans}

THE results of measurements of the highest temperature at which ice particles were formed in a Wilson expansion chamber, using air at the Jungfraujoch Observatory, were recently reported'. Similar measurements have now been made in the air over the Atlantic and Pacific Oceans on board R.M.S. Rangitiki, N.Z.S. Co., during a voyage from London to Wellington (May 10-June 16, 1947).

Measurements made in the 'Horse Latitudes', in the North-East Trade Wind in the Atlantic and in the South-East Trade Wind in the Pacific, gave invariably $-41 \cdot 2^{\circ} \mathrm{C}$. as the ice threshold.

From these measurements and the previous ones at the Jungfraujoch it may be concluded with all probability that there are no nuclei of sublimation in the atmosphere at the cirrus-level, except possibly in cases where they are carried up from ground-level by the violent convection in thunderstorms originating over areas where the air contains industrial pollutions. In such cases the ice threshold will be some $9^{\circ} \mathrm{C}$. higher, and owing to this, such areas might be more subject to showers.

My thanks are due to Sir Nelson Johnson for the loan of the necessary apparatus and to Capt. E. Holland of R.M.S. Rangitiki for providing facilities for the measurements.

$$
\begin{gathered}
\text { Victoria University College, } \\
\text { Wellington, } \\
\text { New Zealand. } \\
\text { June } 23 . \\
\left.{ }^{1} \text { [Nature, 160, } 198(1947)\right] .
\end{gathered}
$$

B. CwILong 